\title{
Iatrogenic encephalocele: a rare complication of vacuum extraction delivery
}

\author{
Hanne-Rinck Jeltema • Eelco W. Hoving
}

Received: 24 July 2011 / Accepted: 26 September 2011 / Published online: 11 October 2011

(C) The Author(s) 2011. This article is published with open access at Springerlink.com

\begin{abstract}
Vacuum extraction is a frequently used form of assisted vaginal delivery. Here we describe a child who was born by vacuum extraction delivery. Days after the birth, a frontal swelling, which was thought to be a caput succedaneum, enlarged. Imaging revealed an iatrogenic encephalocele with a large subcutaneous CSF collection. Surgical reconstruction was performed. A parasagittal dura defect was closed. There was no involvement of the superior sagittal sinus. To our knowledge, encephalocele is an infrequent complication of vacuum extraction delivery, rarely described in literature. The child had a good recovery after the operation, without neurologic deficits.
\end{abstract}

Keywords Iatrogenic encephalocele · Vacuum extraction delivery $\cdot$ Dura defect $\cdot$ Perinatal trauma

\section{Introduction}

Indications for assisted vaginal delivery include prolonged labor or fetal distress. Vacuum extraction delivery is a relatively safe method, known to be less harmful to the mother than forceps extraction [5]. Known complications of vacuum extraction delivery are caput succedaneum, scalp edema, skull fracture, retinal hemorrhage, cephalic hematoma, subgaleal hematoma, and intracranial hematoma [7]. Use of vacuum extraction is contraindicated when the fetus gestational age is

H.-R. Jeltema $(\square) \cdot$ E. W. Hoving

Department of Neurosurgery,

University Medical Centre Groningen,

Hanzeplein 1,

9713 GZ Groningen, the Netherlands

e-mail: j.r.jeltema@nchir.umcg.nl less than 34 weeks because of damage to the scalp and risk of intracranial bleeding [8]. The incidence of complications to the infant after vacuum extraction differs in literature, ranging from $4 \%$ to $26 \%$ for cephalic hematoma, $0 \%$ to $21 \%$ for subgaleal hematoma, and $0.11 \%$ to $0.34 \%$ for intracranial hematoma [7]. Iatrogenic encephalocele with an enlarging subcutaneous CSF collection is a rare complication of vacuum extraction delivery.

\section{Case report}

A female infant was born after a gestation of 36 weeks with a birth weight of 2,575 g, as the child of a nulliparous mother. Because of parietal presentation during labor, a vacuum extraction-assisted delivery was performed. Two attempts with the vacuum pump were done. The child was born with what was regarded as a frontal caput succedaneum. The baby was clinically observed for 4 days after birth because of prematurity. After this period the child was discharged home. On day 6 after birth, the parents observed enlargement of the frontal swelling (Fig. 1), which was previously regarded to be the caput succedaneum. There were also bilateral orbital hematomas visible from day 4 after birth.

Because of the enlargement of the swelling, the child was referred from the relatively small hospital where it was born, to the neurosurgery department of our academic medical center. On admission the baby was alert and hemodynamically stable. The intake was normal. There was no hemiparesis or other neurologic complaint. The swelling measured approximately $10 \times 7 \mathrm{~cm}$. Ophthalmologic investigation showed no retinal hemorrhages.

An MRI scan was performed, revealing herniation of brain tissue through a dural tear near the fontanel, with also CSF 


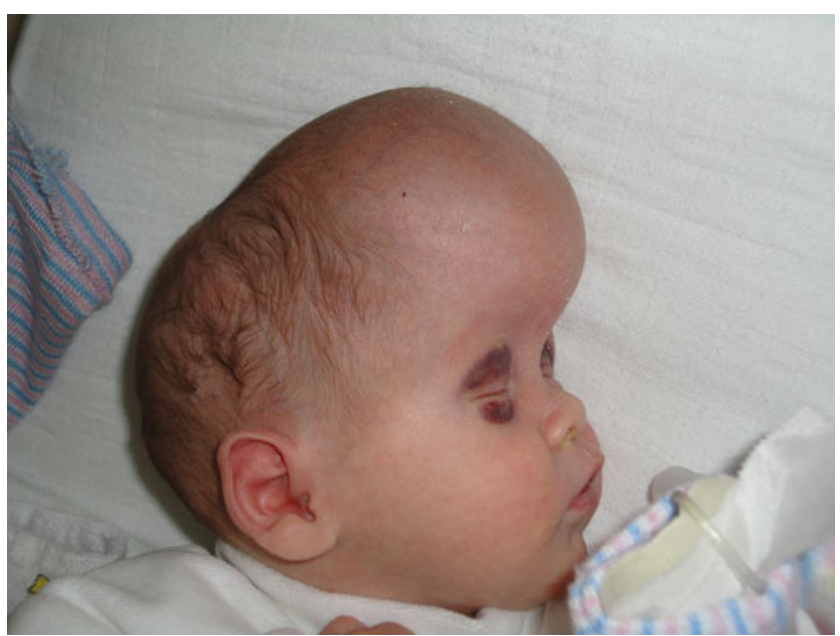

Fig. 1 Photograph on day 6 after birth, showing the bifrontal swelling, previously regarded as a caput succedaneum, and bilateral periorbital hematomas

protruding into the cele (Fig. 2). A puncture was performed. Sanguinolent CSF was aspirated together with neuroglial tissue (confirmed on histopathological examination).

Because of rapid recurrence of the swelling after the puncture, it was decided to perform a surgical reconstruction of the defect. A curved incision was made. Necrotic herniating brain tissue was removed. A frontal dural tear was found just lateral of the superior sagittal sinus. The dural defect could be sutured easily, and no artificial dura graft was needed. The swelling did not recur after surgery. The head circumference remained stable. The infant recovered well after surgery. On the moment of the last follow-up until now, the child was 9 months old. There was a normal development. No motor or cognitive deficits could be found during testing. There were no signs of hydrocephalus. The infant never had insults. Of course further follow-up will be performed.
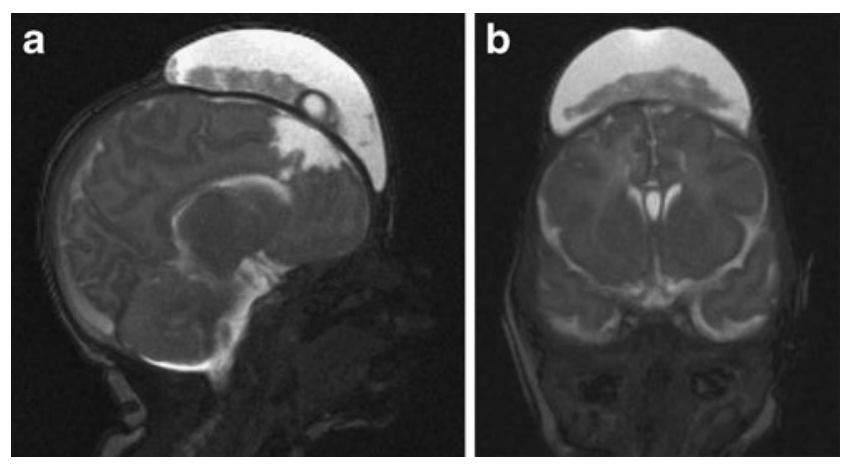

Fig. 2 T2-weighted sagittal (a) and coronal (b) MRI shows a large frontal subcutaneous CSF collection together with necrotic brain tissue herniating through a parasagittal dural tear. The sagittal image reveals a parenchymal tissue defect

\section{Discussion}

Although vacuum extraction delivery is associated with less maternal trauma, neonatal trauma appears to be slightly higher in this form of assisted vaginal delivery compared to forceps extraction [5]. Most complications of vacuum extraction resolve without permanent damage. Few cases of iatrogenic encephalocele have been described as a complication of this procedure. No incidence rate of this adverse event has been described in the literature. We performed a literature search with the terms "vacuum extraction" and "encephalocele" and "brain herniation" on PubMed. Four case reports concerning iatrogenic encephalocele after vacuum extraction could be found. In most of these cases, there was severe neurologic damage to the child. In comparison, the infant described here was in a good clinical condition.

Kau et al. describe the surgical correction of a 15-day-old infant with a pseudomeningocele and frontal brain tissue defect after vacuum extraction. The child did relatively well [1]. Musahl et al. describe a newborn infant with a large bifrontal CSF collection with cephalic hematoma, brain prolapse, and intracranial hematoma due to rupture of the superior sagittal sinus after vacuum extraction. The infant suffered from epilepsy and paresis of the right leg [3]. Kicklighter et al. describe a severely injured child, with extensive damage due to subgaleal hemorrhage and a midline dural tear with herniation of the parietal lobes, caused by vacuum extraction delivery. The child died shortly after delivery [2].

Neumann et al. describe an infant with congenital dural and bony skull defects with also a duplication of the superior sagittal sinus, who suffered from brain herniation and infarction after vacuum extraction. Surgical repair was performed. The further clinical course was complicated by epilepsy and hydrocephalus [4]. Our case report describes an infant in relatively good condition without neurologic or hemodynamic complaints after iatrogenic encephalocele caused by vacuum extraction.

In retrospect one could wonder if imaging had to be performed on day 4 after birth, when the periorbital hematomas appeared, which are very atypical for caput succedaneum, both in timing of appearance and anatomical localization. Like mentioned before, the child was first taken care of in another hospital. The facts that the infant was hemodynamically stable and had no neurologic deficits made the treating physicians choose for a conservative policy without imaging. Only after the frontal swelling enlarged, an MRI scan was performed, showing the encephalocele with the CSF collection.

According to the literature, a true caput succedaneum should diminish in 12-18 h after birth, leaving only a circular area of ecchymosis in some cases [6]. Therefore, in our opinion, imaging should be considered in every child with a 
(large) caput succedaneum that does not diminish in 48-72 $\mathrm{h}$ after birth. We think that enlargement of the swelling more than $24 \mathrm{~h}$ after delivery, neurologic deficits, hemodynamic instability after vacuum extraction with no good explanation after physical examination, or a swelling with a distribution characteristic of a subgaleal hemorrhage requires emergency imaging. As far as we know, no evidence-based guidelines or algorithm exist, concerning the indications for imaging in neonates with head trauma after vacuum extraction.

The initial puncture of the swelling was meant to confirm the diagnosis of iatrogenic encephalocele with a content of both CSF and brain tissue. The rapid filling of the sack after puncturing proved the patent communication with the intracranial cavity. Surgical intervention was indicated to close the dural opening and to prevent reexpansion of the iatrogenic encephalocele. The surgical intervention proved to be effective in our case. There were no developmental abnormalities 9 months after birth of the child. Further follow-up will be performed.

\section{Conclusions}

A newborn infant with a large iatrogenic encephalocele after vacuum extraction delivery is presented. Surgical correction was performed, with closing of the dural defect. The infant made a good recovery.
Open Access This article is distributed under the terms of the Creative Commons Attribution Noncommercial License which permits any noncommercial use, distribution, and reproduction in any medium, provided the original author(s) and source are credited.

\section{References}

1. Kau T, Scharfegger H, Gasser J, Hausegger K (2007) Pseudomeningocele and traumatic brain lesion following vacuum extraction delivery. Arch Neurol 64:1048-1049

2. Kicklighter S, Wolfe D, Perciaccante J (2007) Subgaleal hemorrhage with dural tear and parietal-lobe herniation in association with a vacuum extraction. J Perinatol 27:797-799

3. Musahl C, Schick U (2008) Severe brain injury with rupture of the superior sagittal sinus after vacuum extraction birth. J Neurosurg Pediatr 1:471-473

4. Neuman J, Herweh C, Halatsch M (2010) Congenital duplication of the superior sagittal sinus and parietal encephalocele after vacuum extraction delivery. Acta Neurochir 152:713-716

5. O'Mahony F, Hofmeyr GJ, Menon V (2010) Choice of instruments for assisted vaginal delivery. Cochrane Database Syst Rev 10(11): CD005455

6. Reid J (2007) Neonatal subgaleal hemorrhage. Neonatal Netw 26 (4):219-227

7. Simonson C, Barlow P, Dehennin N, Sphel M, Toppet V, Murillo D, Rozenberg S (2007) Neonatal complications of vacuum-assisted delivery. Obstet Gynecol 109:626-633

8. Suwannachat B, Lumbiganon P, Laopaiboon M (2008) Rapid versus stepwise negative pressure application for vacuum extraction assisted vaginal delivery. Cochrane Database Syst Rev 16(3): CD006636 